\title{
IDENTIFYING BARRIERS TO OFF-SITE CONSTRUCTION USING GREY DEMATEL APPROACH: CASE OF CHINA
}

\author{
Yanhu $\mathrm{HAN}^{1}$, Lufan WANG ${ }^{2 *}$ \\ ${ }^{1}$ School of Economics and Management, Chang'an University, Xian, Shaanxi, 710064, China \\ ${ }^{2}$ Department of Civil and Environmental Engineering, University of Illinois at Urbana-Champaign, \\ Urbana, IL, 61801, United States
}

Received 02 February 2018; accepted 25 May 2018

\begin{abstract}
Off-site construction (OSC) methods have been widely adopted in the construction industry around the world. However, in a lot of developing countries, the application of OSC still lags behind. Although a number of research efforts have focused on identifying the OSC barriers, they are limited to qualitative descriptions, which lacks the understanding of the interrelationships among the barriers. To address this gap, this paper proposed a methodology for identifying the OSC barriers and their cause-effect relationships. The proposed methodology is composed of three phases: (1) a comprehensive literature review and in-depth interview with the OSC industry experts, (2) questionnaire survey and focus group discussion, and (3) grey DEMATEL analysis. The proposed methodology was applied in the context of China's construction industry. The results of the grey DEMATEL analysis provided the cause-effect relationships of the 35 identified OSC barriers, which indicated six important aspects be taken into deeper consideration, such as governmental regulations and incentives, OSC practices and experiences, as well as traditional construction method transformation. The outcomes of this study will support policymakers and OSC participants to identify the influencing OSC barriers and their interrelationships, as well as propose appropriate strategies for overcoming the barriers and broadening the OSC application.
\end{abstract}

Keywords: off-site construction (OSC), barriers, relationship identification, grey DEMATEL analysis, developing countries, case of China.

\section{Introduction}

Conventional on-site construction methods have long been criticized for low productivity, poor quality and safety control, long construction time, and large amount of construction waste. Off-site construction (OSC) methods, as alternatives to the conventional on-site construction methods, have been widely adopted to move the work from construction sites to factories. Compared with the traditional construction methods, numerous benefits of using OSC have been recognized internationally. For example, OSC can utilize resources more effectively, reduce waste generation, improve health and safety performance, provide a controlled environment to maximize construction quality, better integrate supply chain, and enlarge economies of scale (Arif, Egbu 2010).

OSC techniques have been progressively adopted in the construction industry around the world (Jaillon, Poon 2009). For example, the average share of precast concrete systems in the construction industry across the Europe- an Union is $20-25 \%$, and the share is even higher in the northern European countries, which goes up to $40-50 \%$ (Polat 2010). However, despite the well-documented advantages of OSC, the development and popularization degree of OSC in developing countries is still at a low level. For example, the proportion of OSC projects accounted for only $2-3 \%$ in China's newly built buildings (Han et al. 2017). There is, thus, a strong need to identify the obstacles for promoting the implementation of OSC in developing countries.

A number of research efforts have been conducted to explore the barriers inhibiting the development and implementation of OSC (e.g. Arif, Egbu 2010; Mao et al. 2015; Mohamad Kamar et al. 2009; Zhang, Skitmore 2012). However, despite the importance of the existing efforts, they have mostly focused on the experience and summary of pilot projects. Such research efforts are limited to qualitative descriptions without in-depth analyses,

*Corresponding author. E-mail: lwang105@illinois.edu 
which are lack of sufficient accuracy and pertinence. Further studies are thus needed to not only identify the barriers hindering the use of OSC in construction, but also figure out the interrelationships and importance rankings of the barriers for providing better decision-making support to policymakers.

Therefore, to address this gap, this paper proposed a methodology for identifying the OSC barriers and understanding their cause-effect interrelationships. The proposed methodology is based on the integration of three phases: (1) comprehensive literature review and in-depth interview with OSC industry experts, (2) questionnaire survey and focus group discussion, and (3) grey DEMATEL (Decision Making Trial and Evaluation Laboratory) analysis. The first two phases aim to identify a potential set of barriers and determine the relations among these barriers. The grey DEMATEL method aims to mathematically determine the degree of impacts of each barrier and their interrelationships, and to provide insights to policymakers for better improving the development of the OSC industry.

This study applied the proposed methodology in the context of China's OSC industry. China is the world's largest construction market. Revealing the major barriers and their cause-effect relationships in China is especially important and relevant for the popularization of OSC in developing countries, and will add to the body of knowledge and provides more effective management strategies for stakeholders and decision makers.

\section{Problem statement}

China is facing with serious housing shortages because of rapid urbanization. Shown by the "National New Urbanization Plan (2014-2020)", China's central government is implementing an innovative urbanization strategy, which aims to achieve urbanization targets including transferring approximate 100 million rural population to urban areas by 2020 , and reaching $60 \%$ urbanization rate of permanent residents (Cheshmehzangi 2016). However, China’s construction industry is characterized as traditional, labor-intensive, and inefficient, which is unable to meet the booming demand for urban housing. Potential advantages on the application of OSC have been recognized by the central government, practitioners, and researchers. The need for modernizing China's traditional construction industry and tackling the issues of housing demand, sustainability, and innovation-driven development calls for the development of OSC.

However, significant challenges still exist. Compared with developed countries that have adopted OSC for decades (e.g. Germany and Denmark), the development of the OSC techniques in China has just started. The shift from "traditional and on-site construction" to "innovative and industrialized housing" is not easy, especially as traditional construction approaches have been applied in the construction industry for centuries (Zhang, Skitmore 2012).

Although the factors hindering the use of OSC in construction have been studied by a number of researchers (as pointed in the previous section), there is a scarcity amount of research efforts focusing on the barriers in China, and there is a lack of research efforts on finding the interrelationships of the barriers. Therefore, to address the aforementioned knowledge gaps, this study aims to fully investigate the major OSC barriers, mathematically analyze the cause-effect relationships of the barriers, and put forward strategies to conquer the barriers, in the context of China's OSC industry.

In the remainder of this paper, Section 2 briefly introduces the related works in terms of the OSC barriers and the grey DEMATEL method. Section 3 presents the proposed research methodology. Section 4 summarizes the OSC barriers and discusses the findings. Section 5 provides the theoretical and managerial implications based on the results of this study. The last section summarizes the conclusions and looks into future research directions. The research outcomes will benefit policymakers and practitioners in better understanding the OSC barriers, and launching proper regulations and incentives for promoting the application of OSC in China and other developing countries.

\section{Related work}

\subsection{OSC barriers}

The recognition of the importance of OSC technology for enhancing productivity and alleviating the adverse environmental and social effects has resulted in an increasing number of OSC-related research efforts. The identification of the factors that inhibit the adoption of OSC technologies is one of the main research directions (Li et al. 2014). For example, Mohamad Kamar et al. (2009) highlighted five main barriers to the OSC development in Malaysia by literature review and pilot study. The identified barriers include negative perception, readiness issues, cost and equipment, poor planning and regulations, and poor knowledge and awareness issues. Arif and Egbu (2010) pointed out that government policies should be favorable to the manufactured construction initiative. Requisite skills and competencies are needed from a long-term perspective. And strong strategic leaderships from multiple stakeholders, including the government, the construction industry, and the leaders at the municipal level, are needed for motivating and educating the people during the shift in culture and attitude. Zhang and Skitmore (2012) presented nine typical hindrances for applying OSC in China. The top three hindrances reported by Zhang and Skitmore (2012) are higher initial cost, skilled labors with higher wage, and lack of hoist equipment capacity. Mao et al. (2015) investigated the major factors inhibiting the adoption of OSC in mainland China's construction market from the perspective of property developers. The 18 critical factors were categorized into five clusters: industry structure and supply chain, policies and regulations, technological innovation, cost, and market demand. Regulations and policies are the most dominant of the five clusters. Hong et al. (2018) examined the barriers for promoting OSC from a 
cost perspective. They established a cost-benefit analysis framework to explore the basic cost composition of OSC and examined the effect of adopting OSC on the total cost of real building projects.

While the existing efforts in identifying OSC barriers are certainly valuable, they are limited to qualitative descriptions without in-depth analyses, or studies of a single barrier without considering a full range of barriers. However, the barriers hindering the application of OSC are a complex system. The elements are interacting with each other. Yet, to the best of the authors' knowledge, there has been no research for revealing the interrelationships among the OSC barriers thus far. Therefore, the aim of this study is to not only identify the barriers in China's OSC industry, but more importantly, to investigate the causeeffect relationships of the barriers.

\subsection{Grey DEMATEL method}

The DEMATEL method, which was created by the Geneva Research Center of the Battelle Memorial Institute (Fontela, Gabus 1976), is especially practical and useful for visualizing the structure of complicated interdependent relationships by using matrices or digraphs (Chien et al. 2014; Zhou et al. 2011). The traditional DEMATEL method has been widely used in many fields such as industrial symbiosis networks (Bacudio et al. 2016), knowledge management in supply chain (Patil, Kant 2014), and consumer decision-making in e-marketplace (Kumar, Dash 2016). The DEMATEL method supposes that the system under consideration contains a set of factors, and pairwise relations of the factors are determined by a mathematical relation (Tseng 2009). It provides a way to visualize causal relationships among the factors through an impactrelationship map, and is also able to indicate the degree to which factor influence each other (Kabak et al. 2016). In this structural modeling approach, all factors are divided into cause group or effect group. A better understanding of the causal relationships among the system factors can thus be obtained. This feature makes DEMATEL an appropriate tool to solve the cause-effect relationship problem of the OSC barriers in the construction industry. Therefore, this study used the DEMATEL method to classify the barriers hindering the OSC application, and to identify the most critical barriers by analyzing and interpreting the structural cause-effect model. The causal factors having the greatest effect on the system are the most critical barriers that need particular attention.

Before conducting the DEMATEL analysis, the pairwise relationships among the influential factors of the studied problem need to be determined. Such relationships are built based on the personal judgments, preferences, and knowledge of experts or decision-makers. In the traditional DEMATEL method, crisp values are usually used to describe the relationships. However, crisp numbers are inadequate in the real world, due to the vagueness and imprecise judgments existed in human's decisionmaking (Liang et al. 2016). For example, it is possible that there is inaccurate and inadequate expert knowledge of OSC. Most of the OSC practices in China are pilot projects. The researchers and practitioners could have a short of experience and deviated opinion when building the relationships among the influential factors. Grey set theory is thus needed for solving this kind of problem.

Grey set theory is an important tool for supporting uncertain decisions. It can make the decision results closer to reality by constructing a flexible decision model using grey interval numbers. In reality, the evaluation given by experts or decision makers on related fields is always expressed in linguistic expressions instead of crisp values. The grey set theory can be implemented to measure the ambiguous concepts associated with human's subjective judgements by combining linguistic variables (Lin 2013). In particular, when experts make judgments using incomplete or conflicting information, or when they are aware of the lack of expertise in some situations, the contributions of the grey set theory will increase (Kabak et al. 2016).

To benefit from the advantages of both the DEMATEL method and the grey set theory, the so-called "grey DEMATEL" (Govindan et al. 2016) or "fuzzy DEMATEL" (Lin 2013) method has been proposed by combining the DEMATEL method and the grey logic. The extended method has been widely used to address the complicated and intertwined problems (e.g. Lin et al. 2008; Vakil alroaia et al. 2012; Zhou et al. 2011, etc.), to help researchers with better decision support in an environment of imperfect information characterized by linguistic expressions and incomplete/inaccurate personal judgements of experts (Kabak et al. 2016). Therefore, the grey DEMATEL method was applied in this study, to obtain a more accurate analysis for identifying the OSC barriers and their cause-effect relationships.

This research contributes to the body of knowledge in three main ways. First, it proposed an OSC barriers and interrelationships identification methodology. Second, it identified the linkages and cause-effect relationships among various barriers hindering the OSC industry. Third, by highlighting the cause-effect relationships among these barriers, this research enables a better decision-making support for policymakers in preparing more effective strategic plans to promote the development of the OSC industry.

\section{Methodology}

The methodology used in this study is a combination of literature review, in-depth interview, questionnaire survey, focus group discussion, and grey DEMATEL analysis.

\subsection{Literature review and in-depth interview}

A comprehensive review of previous studies was performed to identify a potential set of barriers that are hindering the OSC practice. The authors reviewed a wide range of literatures from various top-ranking journals and conference proceedings. For example, Blismas et al. 
Table 1. Preliminary barriers to OSC after literature review and in-depth interview

\begin{tabular}{|c|c|c|}
\hline Dimensions & Potential barriers & References \\
\hline \multirow[t]{5}{*}{ Economic $\left(D_{1}\right)$} & High initial set-up cost for manufacturer $\left(B_{1}\right)$ & Jaillon and Poon (2009), Lovell and Smith (2010) \\
\hline & $\begin{array}{l}\text { High cost for contractor including construction, } \\
\text { transportation cost and cranage cost }\left(\mathrm{B}_{2}\right)\end{array}$ & Jaillon and Poon (2009), Pan et al. (2007) \\
\hline & Increased design fees $\left(B_{3}\right)$ & Blismas and Wakefield (2008) \\
\hline & High bidding price for contractors $\left(\mathrm{B}_{4}\right)$ & Added after in-depth interview \\
\hline & Shortage of market demand $\left(B_{5}\right)$ & Lovell and Smith (2010) \\
\hline \multirow[t]{14}{*}{$\begin{array}{l}\text { Technological } \\
\left(\mathrm{D}_{2}\right)\end{array}$} & $\begin{array}{l}\text { Longer lead-in time for pre-planning and design } \\
\text { during design stage }\left(\mathrm{B}_{6}\right)\end{array}$ & $\begin{array}{l}\text { Blismas and Wakefield (2008), Blismas et al. (2005), } \\
\text { Goodier and Gibb (2005) }\end{array}$ \\
\hline & Traditional design process unsuited to OSC $\left(\mathrm{B}_{7}\right)$ & Blismas and Wakefield (2008) \\
\hline & $\begin{array}{l}\text { Not easy to modify design scheme especially once } \\
\text { manufacture has commenced }\left(B_{8}\right)\end{array}$ & $\begin{array}{l}\text { Blismas et al. (2005), Jaillon and Poon (2009), Pan } \\
\text { et al. (2007) }\end{array}$ \\
\hline & $\begin{array}{l}\text { Transportation technology of prefabricated elements } \\
\text { and access to the construction site }\left(B_{9}\right)\end{array}$ & $\begin{array}{l}\text { Blismas and Wakefield (2008), Blismas et al. (2005), } \\
\text { Jaillon and Poon (2009) }\end{array}$ \\
\hline & Difficulty to the storage of prefabricated elements $\left(B_{10}\right)$ & Blismas et al. (2005), Jaillon and Poon (2009) \\
\hline & Durability of prefabrication unproven $\left(\mathrm{B}_{11}\right)$ & Lovell and Smith (2010) \\
\hline & $\begin{array}{l}\text { Low tolerances increase problems when fitting } \\
\text { components on site }\left(B_{12}\right)\end{array}$ & Blismas and Wakefield (2008) \\
\hline & Lack of practices and experiences $\left(B_{13}\right)$ & $\begin{array}{l}\text { Goodier and Gibb (2005), Mohamad Kamar et al. } \\
\text { (2009) }\end{array}$ \\
\hline & Dependence of traditional construction method $\left(\mathrm{B}_{14}\right)$ & Mohamad Kamar et al. (2009) \\
\hline & Organizational mechanism and culture $\left(\mathrm{B}_{15}\right)$ & Pan et al. (2007) \\
\hline & Monotony of structure type $\left(\mathrm{B}_{16}\right)$ & Jaillon and Poon (2009) \\
\hline & Monopoly of techniques $\left(\mathrm{B}_{17}\right)$ & Mohamad Kamar et al. (2009), Patil and Kant (2014) \\
\hline & $\begin{array}{l}\text { Poor performance of precast concrete in earthquake } \\
\left(\mathrm{B}_{18}\right)\end{array}$ & Polat (2010) \\
\hline & $\begin{array}{l}\text { Education and training still focused on current } \\
\text { practices }\left(B_{19}\right)\end{array}$ & Blismas and Wakefield (2008) \\
\hline \multirow[t]{8}{*}{ Industrial $\left(\mathrm{D}_{3}\right)$} & Fragmented industry structure $\left(B_{20}\right)$ & Mohamad Kamar et al. (2009), Pan et al. (2007) \\
\hline & $\begin{array}{l}\text { Unable to achieve good communication and } \\
\text { collaboration among parties }\left(\mathrm{B}_{21}\right)\end{array}$ & Blismas et al. (2005), Polat (2010) \\
\hline & $\begin{array}{l}\text { Unbalance and uncertainty between component supply } \\
\text { and demand }\left(\mathrm{B}_{22}\right)\end{array}$ & Added after in-depth interview \\
\hline & Risk adverse culture $\left(\mathrm{B}_{23}\right)$ & Pan et al. (2007) \\
\hline & Construction adversary culture $\left(\mathrm{B}_{24}\right)$ & Added after in-depth interview \\
\hline & Reluctance to innovation $\left(\mathrm{B}_{25}\right)$ & Pan et al. (2007) \\
\hline & $\begin{array}{l}\text { Lack of related organizations, such as local R\&D } \\
\text { institutes and services, testing institute to prefabricated } \\
\text { components, experienced design consultancy and } \\
\text { designers, manufacturers and suppliers of prefabricated } \\
\text { components, and production facility logistics, etc. }\left(B_{26}\right)\end{array}$ & Mohamad Kamar et al. (2009), Pan et al. (2007) \\
\hline & Lack of skilled industrial worker $\left(\mathrm{B}_{27}\right)$ & Added after in-depth interview \\
\hline \multirow[t]{4}{*}{ Social $\left(D_{4}\right)$} & $\begin{array}{l}\text { Lessons and attitudinal barriers due to historic failures } \\
\left(\mathrm{B}_{28}\right)\end{array}$ & Pan et al. (2007) \\
\hline & $\begin{array}{l}\text { Lack of awareness of prefabrication by the market and } \\
\text { public }\left(\mathrm{B}_{29}\right)\end{array}$ & $\begin{array}{l}\text { Lovell and Smith (2010), Mohamad Kamar et al. } \\
\text { (2009) }\end{array}$ \\
\hline & Size and load restrictions on transportation $\left(B_{30}\right)$ & Polat $(2010)$ \\
\hline & Small site dimensions in dense urban area $\left(\mathrm{B}_{31}\right)$ & Jaillon and Poon (2009) \\
\hline \multirow[t]{4}{*}{ Legal $\left(D_{5}\right)$} & $\begin{array}{l}\text { Lack of design codes and standards for prefabricated } \\
\text { components }\left(\mathrm{B}_{32}\right)\end{array}$ & $\begin{array}{l}\text { Blismas and Wakefield (2008), Goodier and Gibb } \\
\text { (2005), Mohamad Kamar et al. (2009) }\end{array}$ \\
\hline & Lack of construction quality acceptance criteria $\left(\mathrm{B}_{33}\right)$ & Added after in-depth interview \\
\hline & Inadequate skills qualifications $\left(\mathrm{B}_{34}\right)$ & Blismas and Wakefield (2008) \\
\hline & Lack of governmental regulations and incentives $\left(B_{35}\right)$ & $\begin{array}{l}\text { Blismas and Wakefield (2008), Lovell and Smith } \\
\text { (2010), Mohamad Kamar et al. (2009) }\end{array}$ \\
\hline
\end{tabular}


(2005) highlighted the project-level constraints on the use of off-site production in construction. The constraints were grouped into four broad themes covering the array of specific constraints, and were ranked using cumulative scores. The most prominent constraints were process constraints, followed by value, supply-chain and knowledge constraints. The barriers of OSC in the Australian construction industry were summarized to four aspects: process change, high capital expenditure, supply-chain restrictions and regulatory restrictions (Blismas, Wakefield 2008). In Hong Kong, ten hindrances in applying prefabrication were studied, and the top three hindrances are inflexible for changes of design, lack of research information, and higher initial construction cost (Tam et al. 2007). The case studies conducted by Jaillon and Poon (2009) showed that the barriers of adopting prefabrication were generally the limitation in element dimension due to problems with transportation and lifting equipment, small site dimensions in dense urban area, and lack of on-site storage area for precast components.

The in-depth interviews with the OSC industry experts are conducted after the literature review, to further inspect the comprehensiveness and rationality of the identified barriers. The experts are China's representative contractors, developers, designers, precast component manufacturers, policymakers, and academicians. The in-depth interviews include two steps. First, the interviewees are asked to express their views and comments freely on the current OSC development in China based on their experience. Second, the interviewees are asked to answer questions about whether the factors obtained from the literature review covered all the potential barriers, and whether any factors need to be merged or split.

The literature review and expert interviews identified an initial list of the preliminary barriers inhibiting China's OSC practices, which became the objects for further analysis. Overall, a total of 35 barriers from economic, technological, industrial, social, and legal dimensions were selected, as shown in Table 1.

\subsection{Questionnaire survey and focus group discussion}

The questionnaire survey and focus group discussion aim to determine the direct-influenced matrix. The direct-influenced matrix is formed by the mutual influential relationships between any two factors in Table 1 .

The questionnaire was composed of three sections. Section 1 introduced the background and purpose of this study to the respondents. Section 2 was composed of demographic questions for collecting the personal information of the respondents, including the respondent's occupation, affiliation, and years of construction experience. This section is to verify the eligibility of the respondents and representativeness of the collected data. In Section 3, respondents were asked to make his/her own judgment on the influential degree between each pair of barriers in Table 1, and report their answers by using the linguistic
Table 2. Matchup relationships between linguistic terms and the corresponding grey number

\begin{tabular}{|lll|}
\hline \multicolumn{1}{|c}{ Linguistic terms } & Abbreviation & Grey numbers \\
\hline No influence & $\mathrm{N}$ & {$[0,0]$} \\
Extremely low influence & $\mathrm{EL}$ & {$[0,1]$} \\
Moderately low influence & $\mathrm{ML}$ & {$[1,2]$} \\
Medium influence & $\mathrm{M}$ & {$[2,3]$} \\
Moderately high influence & $\mathrm{MH}$ & {$[3,4]$} \\
Extremely high influence & $\mathrm{EH}$ & {$[4,5]$} \\
\hline
\end{tabular}

terms presented in Table 2. Initial direct-influenced matrixes were then generated by each respondent.

Each element in the direct-influenced matrix is obtained from the subjective understanding and evaluation of each respondent. So, the resulted direct-influenced matrices varied across respondents, as the respondents may have different understandings of the influential degree among the barriers. Therefore, the focus group discussion aims to evaluate the results of the questionnaire survey, and gain a systematic and consentaneous view on the decisions of the direct-influenced matrixes.

Seven external OSC experts were invited to participate in the focus group discussion, including two professors who have conducted in-depth OSC-related research, two precast component manufacturers who have profound understandings of OSC, one engineer from the real-estate development firm and one from the contractor who have gained wide experience of OSC practices, and one OSC administrative executor. An experienced moderator was chosen to host the focus group meeting. The moderator introduced the meeting rules and the related knowledge about OSC to the participants. The invited experts were then asked to evaluate and discuss the initial direct-influenced matrixes obtained from the questionnaire survey. Based on the rule, "the minority is subordinate to the majority" (Ren et al. 2013), and the consensus within all the experts, the initial direct-influenced matrixes were merged, and a final direct-influenced matrix was generated.

\subsection{Grey DEMATEL analysis}

The procedure of the grey DEMATEL method can be detailed as the following steps.

Step 1: Determining the direct-influenced matrix. Direct-influenced matrix is the basis of the grey DEMATEL analysis. The questionnaire survey and focus group discussion, as was explained in Section 3.2, was used to get the direct-influenced matrix of the 35 OSC barriers. The respondents were asked to present their opinions and views based on the pairwise relationships among the OSC barriers, using the linguistic terms following Table 2. And external experts obtained a final direct-influenced matrix after evaluating and discussing the survey results.

Step 2: Determining the grey direct-influenced matrix. Transform all the linguistic terms into grey numbers according to the matchup criteria in Table 2. The influence of 
factor $i$ on factor $j$ determined by the experts was denoted by $\otimes a_{i j}=\left[a_{i j}^{-}, a_{i j}^{+}\right]$. Here, $\otimes a$ is a grey number, which represents that the information of the number is insufficient and incomplete, and it belongs to a range instead of a crisp value (Lin 2013). For $i=j$, the diagonal elements are set to $[0,0]$. The results provided by the stakeholders or decision makers can form an $n$ by $n$ matrix, as shown in Eqn (1):

$$
\otimes A^{k}=\left|\begin{array}{cccc}
0,0] & \otimes a_{12} & \cdots & \otimes a_{1 n} \\
\otimes a_{21} & {[0,0]} & \cdots & \otimes a_{2 n} \\
\vdots & \vdots & \ddots & \vdots \\
\otimes a_{n 1} & \otimes a_{n 2} & \cdots & {[0,0}
\end{array}\right|,
$$

where $\otimes A$ is the grey direct-influenced matrix, $k$ is the number of respondents, and $\otimes a_{i j}=\left[a_{i j}^{-}, a_{i j}^{+}\right]$represents the element in $\otimes A$.

Step 3: Normalize the initial direct-relation matrix. The normalized initial direct-relation matrix $D$ can be determined by Eqns (2) and (3):

$$
\begin{aligned}
& s=\max \left(\max _{1 \leq i \leq n} \sum_{1 \leq j \leq n}^{n} a_{i j}^{+}, \max _{1 \leq j \leq n} \sum_{1 \leq i \leq n}^{n} a_{i j}^{+}\right) ; \\
& \otimes D=\left[\otimes d_{i j}\right]_{n \times n}=\left[\left(d_{i j}^{-}, d_{i j}^{+}\right)\right]_{n \times n}=\frac{\otimes A}{s},
\end{aligned}
$$

where $\otimes D$ is the normalized initial direct-relation matrix, and $s$ is the auxiliary parameter for normalizing the initial direct-relation matrix.

Step 4: Calculate the total relation matrix. The powers of $\otimes D$ represent the indirect effects between any two factors. The total relation matrix $\otimes T$ can be calculated by Eqns (4)-(8):

$$
\begin{aligned}
\otimes T= & {\left[\otimes t_{i j}\right]_{n \times n}=\left[\left(t_{i j}^{-}, t_{i j}^{+}\right)\right]_{n \times n}=} \\
& \otimes D+(\otimes D)^{2}+\cdots+(\otimes D)^{\infty} ; \\
T^{-}= & {\left[t_{i j}^{-}\right]_{n \times n}=D^{-}\left(I-D^{-}\right)^{-1} ; } \\
T^{+}= & {\left[t_{i j}^{+}\right]_{n \times n}=D^{+}\left(I-D^{+}\right)^{-1} ; } \\
D^{+}= & {\left[d_{i j}^{+}\right]_{n \times n} ; } \\
D^{-}= & {\left[d_{i j}^{-}\right]_{n \times n}, }
\end{aligned}
$$

where $\otimes T$ represents the total relation matrix, and $I$ is the identity matrix.

Step 5: Determine the prior sequence of the factors from most to least important, and identify the cause-effect relations. The total effect that directly and indirectly exerted by the $i$-th factor, is denoted by $\otimes R_{i}$, and could be calculated by Eqn (9):

$$
\otimes R_{i}=\sum_{j=1}^{n} \otimes t_{i j} .
$$

The total effect including direct and indirect effects received by the $j$-th factor, is denoted by $\otimes C_{j}$, and could be calculated by Eqn (10):

$$
\otimes C_{j}=\sum_{i=1}^{n} \otimes t_{i j} .
$$

The sum $\otimes R_{i}+\otimes C_{j}$ represents the total effects given and received by the $i$-th factor. In other words, $\otimes R_{i}+\otimes C_{j}$ is a measure of the degree of the importance of the $i$-th factor in the system. The prior sequence of the $n$ factors could be determined based on the value of $\otimes R_{i}+\otimes C_{j}$. The bigger the value of $\otimes R_{i}+\otimes C_{j}$, the more important the factor is. The difference $\otimes R_{i}-\otimes C_{j}$ is called relation. It shows the net effect that is contributed by the $i$-th factor to the system. When $\otimes R_{i}-\otimes C_{j}>0$, the $i$-th factor is a net cause, which means the factor belongs to the "cause group". On the contrary, when $\otimes R_{i}-\otimes C_{j}<0$, the $i$-th factor is a net receiver/result, which means the factor belongs to the "effect group". The fuzzy numbers were converted to crisp values by taking the average. The results were validated through feedbacks from industrial and academic experts.

\section{Results and discussion}

Table 3 shows the demographic information of the respondents, including their affiliation, occupation type, professional title, and work experience. According to Table 3, $60 \%$ of the respondents work in prefabricated component factories, construction firms, or academia. More than $90 \%$ of the respondents are engineers, managers, or researchers. And managers accounted for the single largest proportion, which is about $34 \%$. The majority (about $84 \%$ ) of the respondents are with senior titles or above, which indicates that the responses of the survey are representative and reliable. However, in terms of the OSC working experience, half of the respondents have only 1-3 years of experience, which indicates that there is a lack of professionals with rich experience in China's OSC industry, and therefore, identifying and overcoming the OSC barriers is a must towards promoting the development of OSC.

The OSC barriers were analyzed and structured following the proposed methodology. Since the 35 potential barriers have been determined through literature review and in-depth interview, questionnaire survey and focus group discussion are then conducted to collect evaluation data about the pairwise interrelationships among the selected OSC barriers. The direct-influenced matrix (Table 4), which was determined by the focus group discussion and expressed in linguistic terms, was thus obtained. For example, if the experts decided that high construction cost for contractor including transportation cost and cranage cost $\left(\mathrm{B}_{2}\right)$ has "Extremely high influence $(\mathrm{EH})$ " on the high bidding price for contractors $\left(\mathrm{B}_{4}\right)$ after the final discussion, " $\mathrm{EH}$ " will be filled in row $\mathrm{B}_{2}$ and column $\mathrm{B}_{4}$ of Table 4. Next, according to the matchup of the linguistic terms and grey numbers in Table 2, the linguistic terms in Table 4 were transformed into grey numbers, as shown in Table 5. Then the normalized direct-influenced matrix and 
the total relation matrix were calculated using Eqns (2)(3), and Eqns (4)-(8). Finally, indexes and scores of each barrier were obtained by using Eqns (9) and (10), as shown in Table 6. Based on the above outcomes, the cause-effect relationship diagram was plotted by mapping the data points (crisp $\otimes R_{i}+\otimes C_{j}$, crisp $\otimes R_{i}-\otimes C_{j}$ ), as shown in Figure 1.
The importance of the barriers was calculated and ranked by using $\otimes R_{i}+\otimes C_{j}$ (Table 6). Of the 35 barriers, the final prior sequence of the five most important barriers are dependence of traditional construction method $\left(\mathrm{B}_{14}\right)$, lack of practices and experiences $\left(B_{13}\right)$, high bidding price for contractors $\left(\mathrm{B}_{4}\right)$, high cost for contractor including

Table 3. Summary of the demographic information of respondents

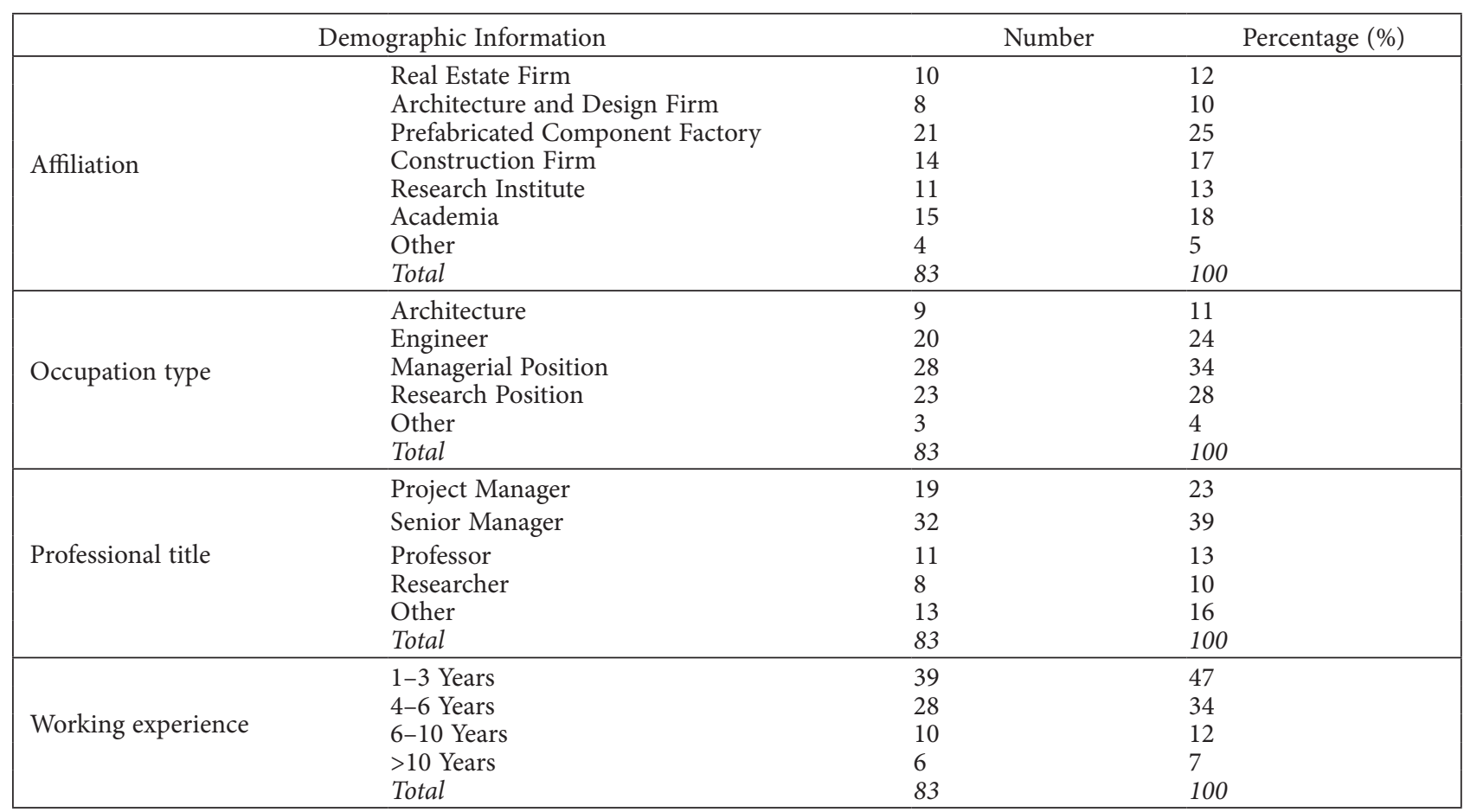

Note: Round off errors may occur in percentage calculation.

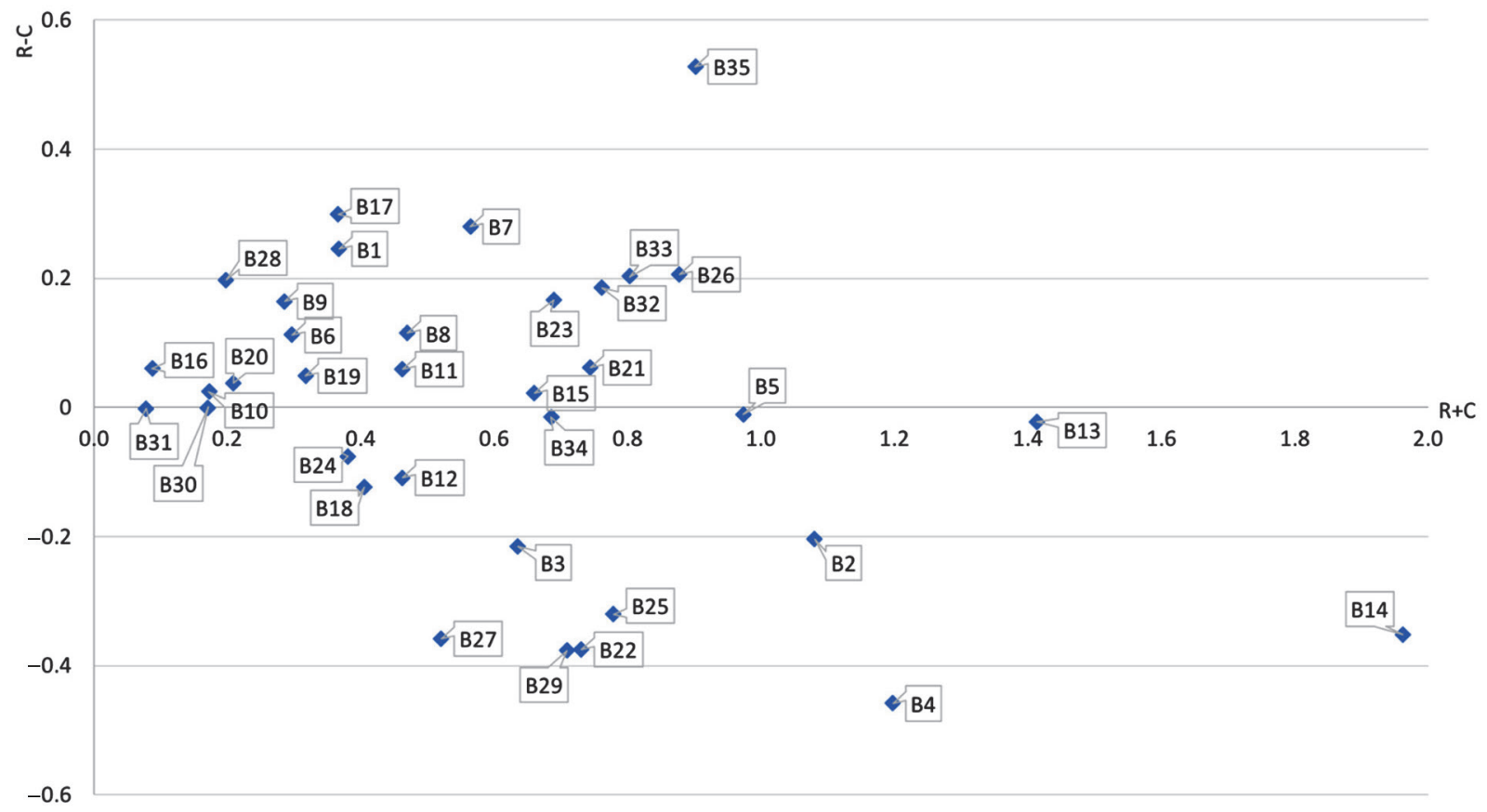

Figure 1. Cause-effect relationship diagram 


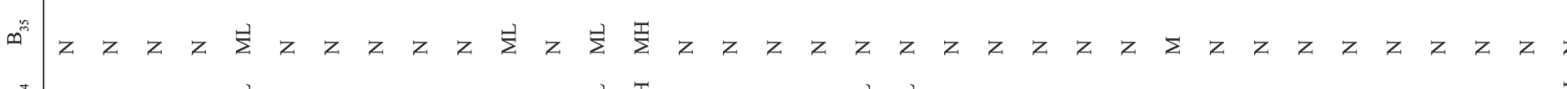

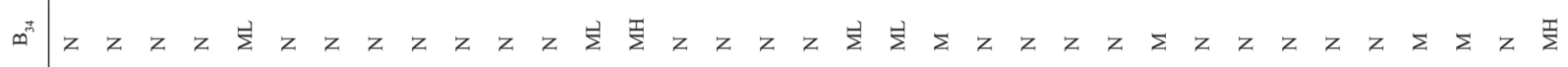

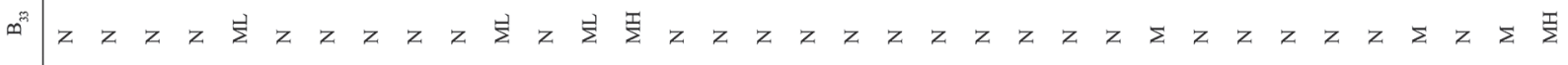

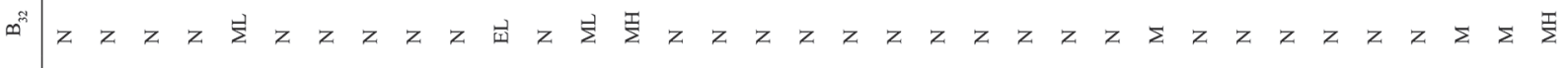

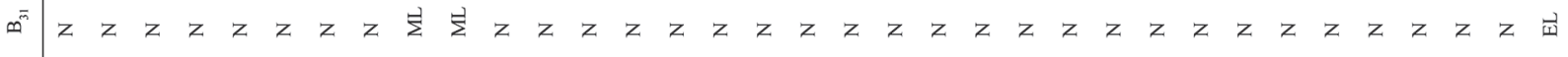

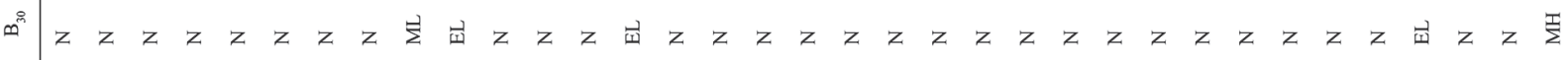
ल

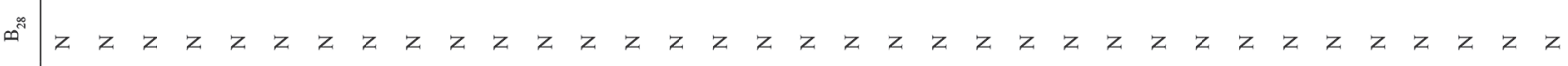
舟

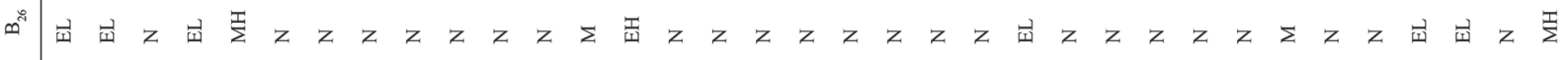

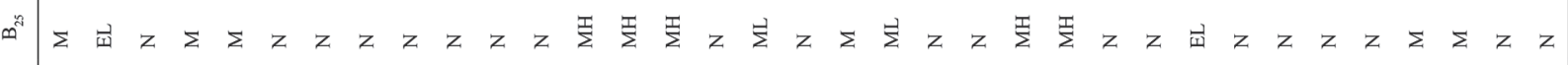

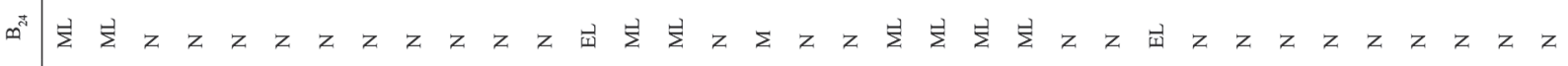

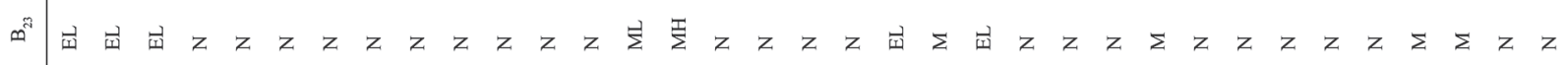

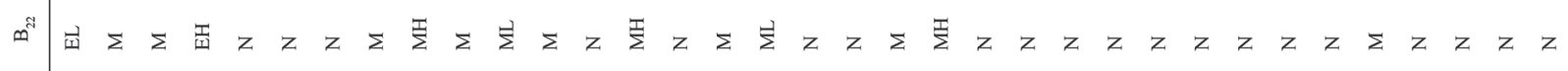
ल

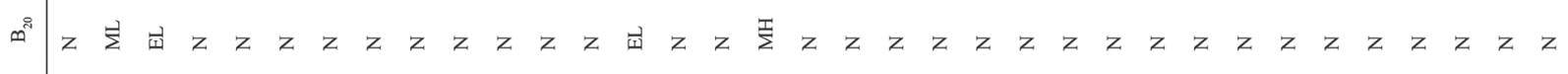
$\infty^{9} z$ 岃 $\infty$

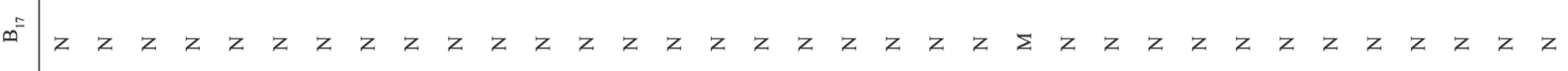

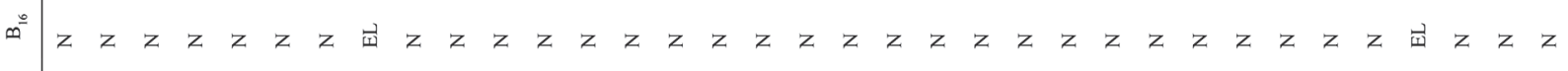

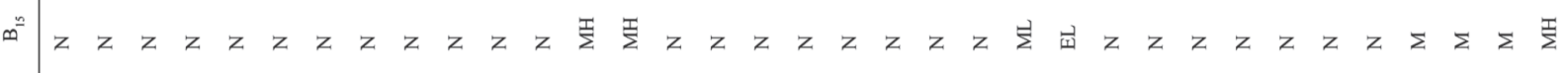

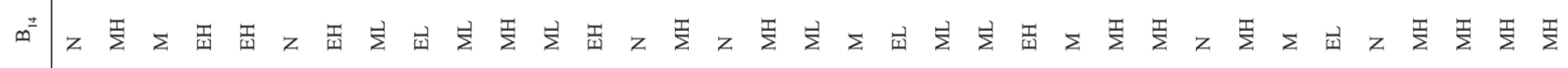

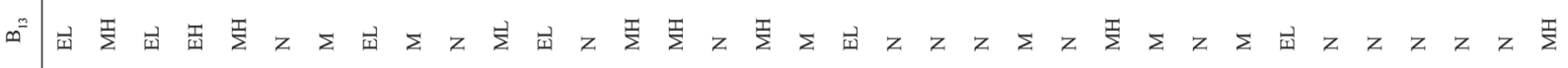

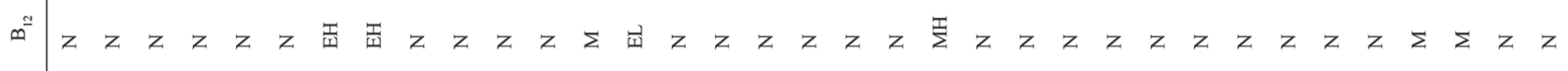

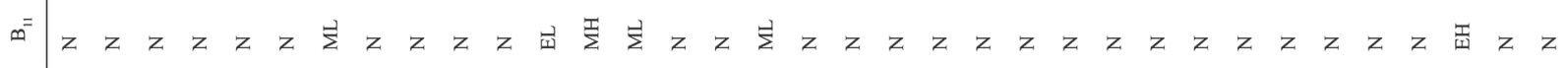

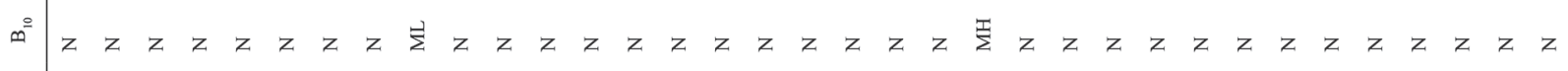

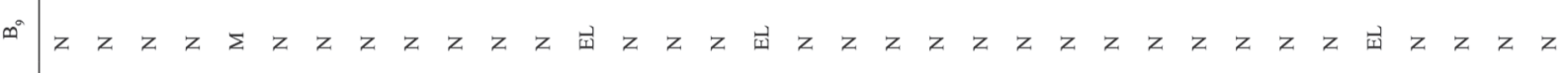

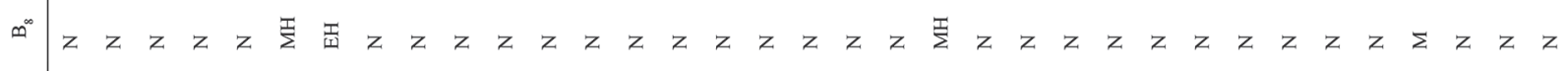
m

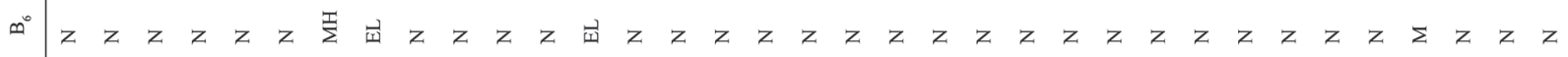

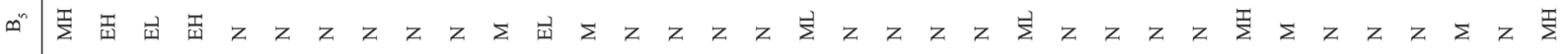

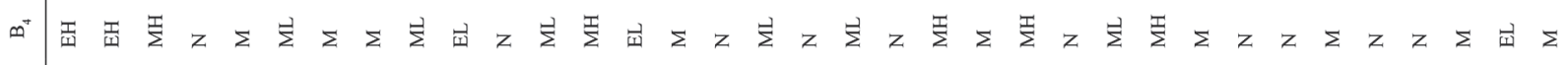

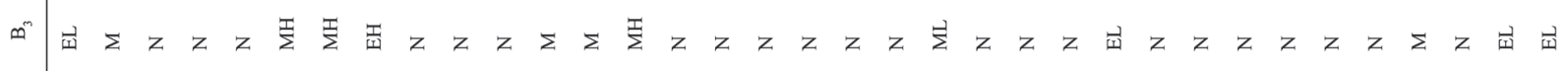

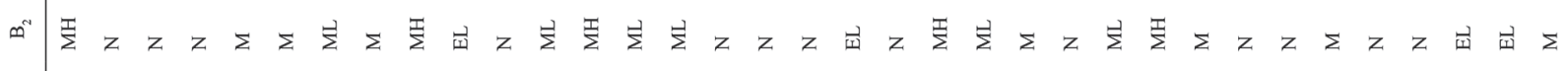

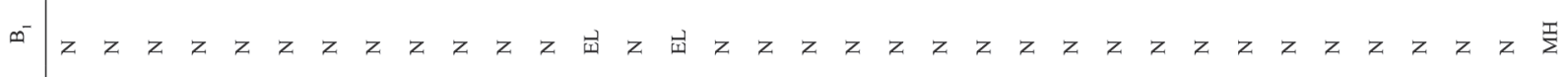

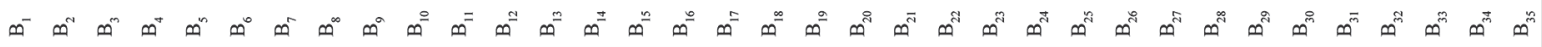




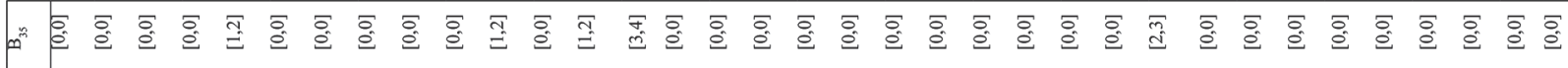

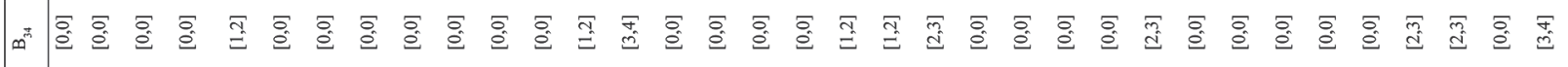

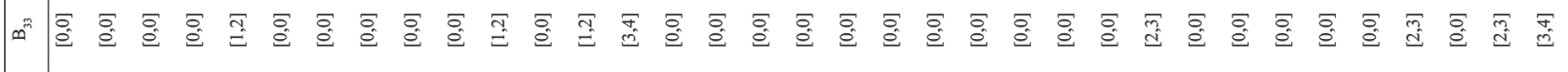

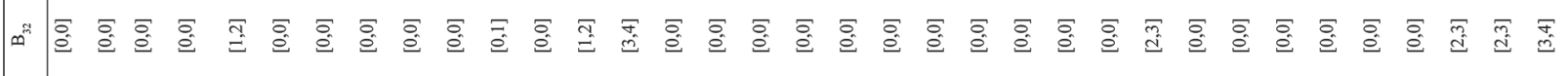

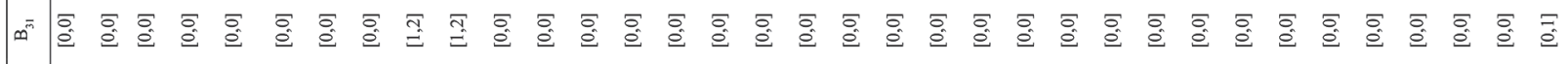

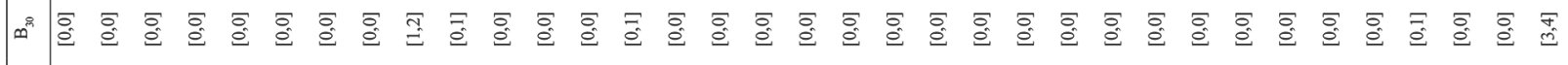

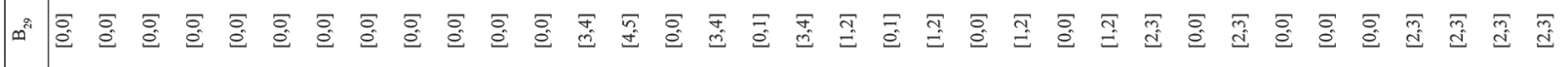

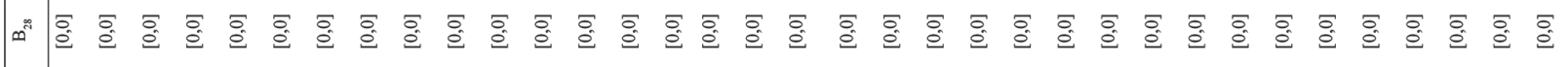

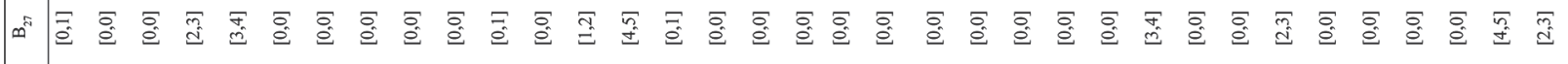

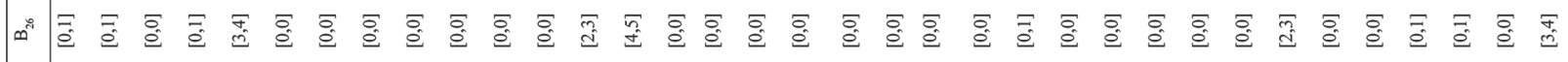

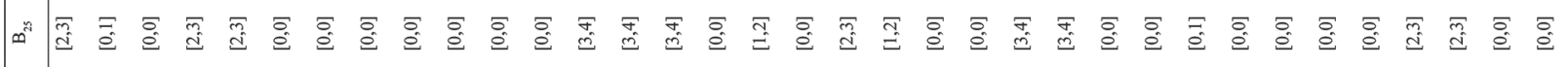

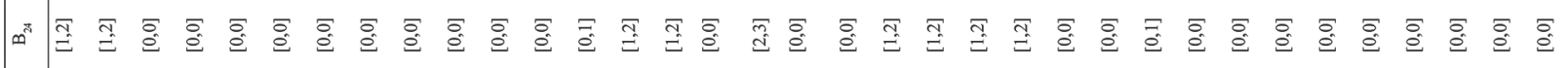

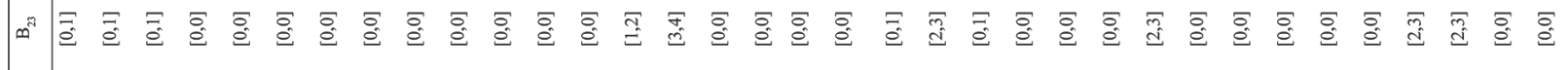

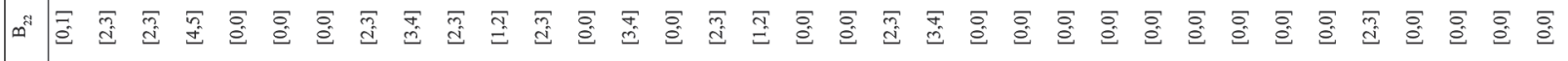

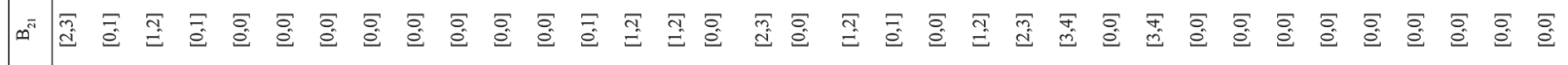

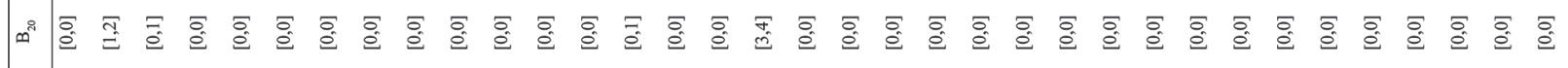

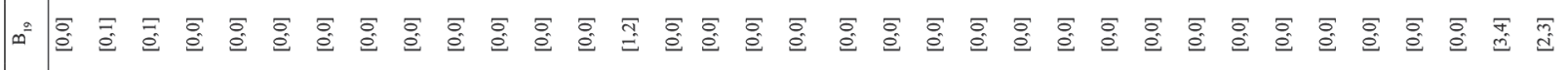

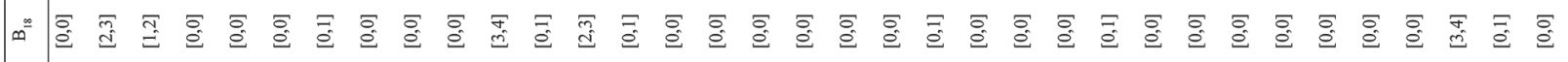

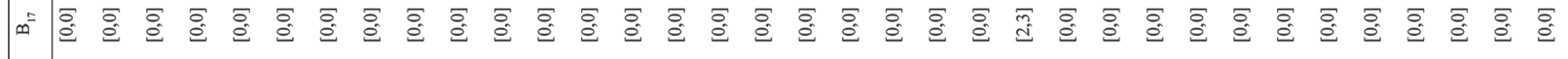

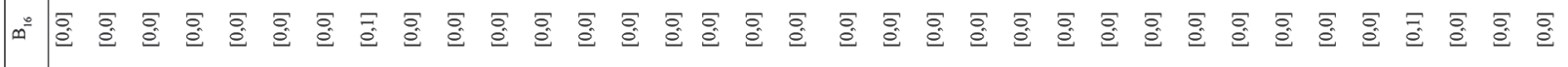

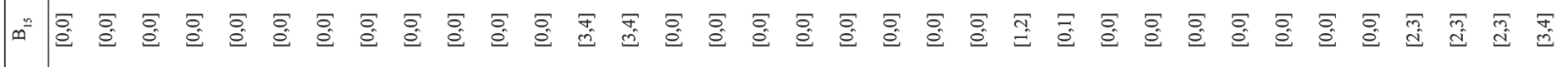

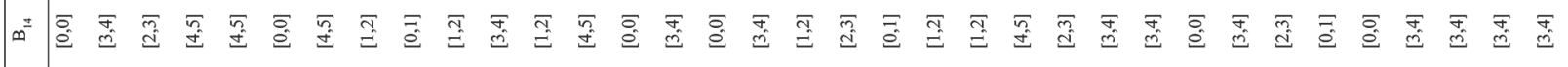

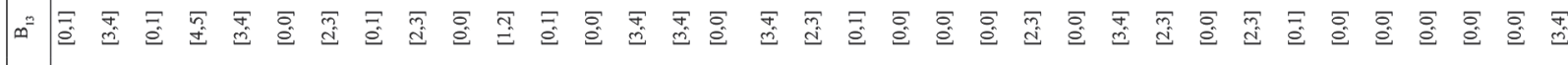

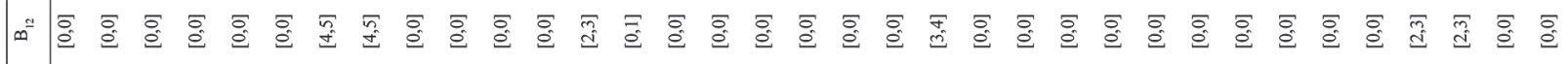

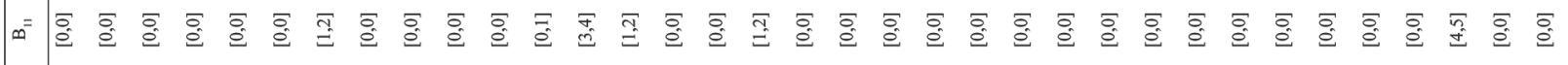

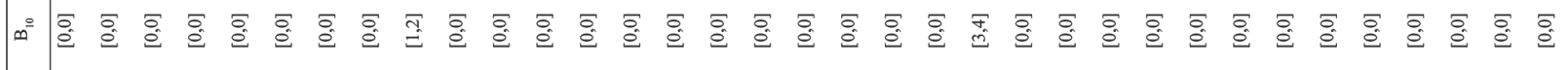

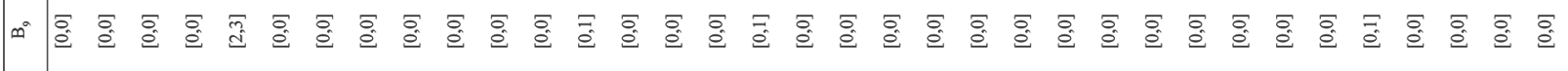

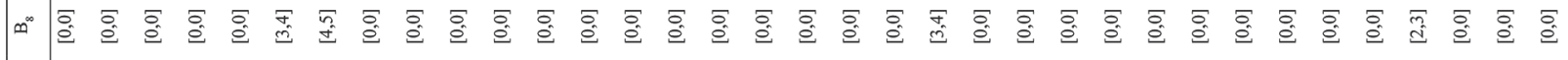

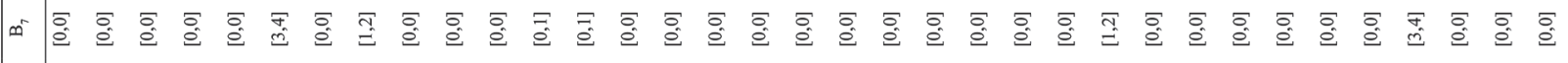

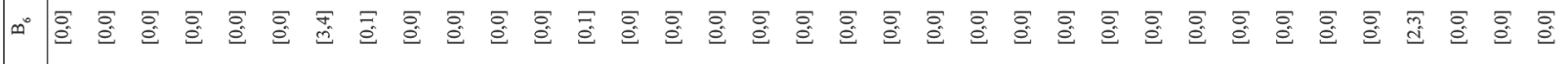

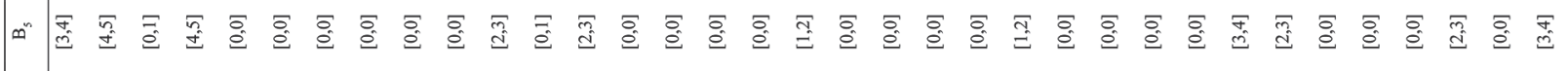

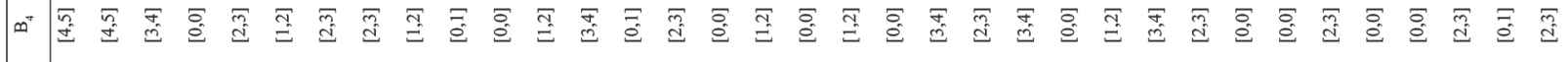

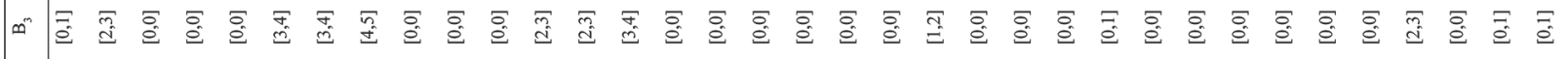

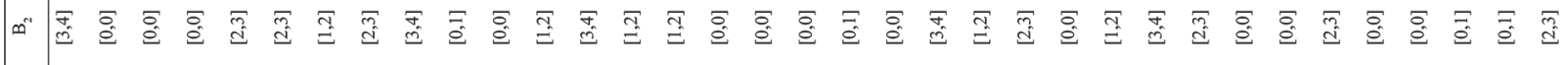

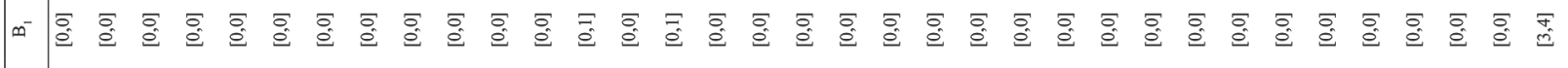

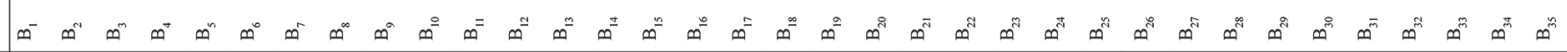


Table 6. Results of grey DEMATEL analysis

\begin{tabular}{|c|c|c|c|c|c|c|c|c|c|}
\hline Barriers & $\otimes R_{i}$ & $\otimes C_{j}$ & $\otimes R_{i}+\otimes C_{j}$ & Crisp $\otimes R_{i}+\otimes C_{j}$ & Rank & $\otimes R_{i}-\otimes C_{j}$ & Crisp $\otimes R_{i}-\otimes C_{j}$ & Cause relation & Effect relation \\
\hline $\mathrm{B}_{1}$ & {$[0.198,0.414]$} & {$[0.035,0.087]$} & {$[0.233,0.501]$} & 0.367 & 25 & {$[0.163,0.327]$} & 0.245 & $\sqrt{ }$ & \\
\hline $\mathrm{B}_{2}$ & {$[0.297,0.579]$} & {$[0.444,0.840]$} & {$[0.741,1.419]$} & 1.080 & 4 & {$[-0.147,-0.261]$} & -0.204 & & $\sqrt{ }$ \\
\hline $\mathrm{B}_{3}$ & {$[0.121,0.298]$} & {$[0.297,0.553]$} & {$[0.418,0.850]$} & 0.634 & 17 & {$[-0.176,-0.255]$} & -0.216 & & $\sqrt{ }$ \\
\hline $\mathrm{B}_{4}$ & {$[0.276,0.462]$} & {$[0.601,1.054]$} & {$[0.878,1.516]$} & 1.197 & 3 & {$[-0.325,-0.592]$} & -0.458 & & d \\
\hline $\mathrm{B}_{5}$ & {$[0.348,0.615]$} & {$[0.359,0.625]$} & {$[0.707,1.240]$} & 0.974 & 5 & {$[-0.012,-0.01]$} & -0.011 & & $\sqrt{ }$ \\
\hline $\mathrm{B}_{6}$ & {$[0.154,0.255]$} & {$[0.059,0.126]$} & {$[0.213,0.381]$} & 0.297 & 28 & {$[0.095,0.130]$} & 0.112 & $\sqrt{ }$ & \\
\hline $\mathrm{B}_{7}$ & {$[0.316,0.528]$} & {$[0.084,0.199]$} & {$[0.400,0.728]$} & 0.564 & 18 & {$[0.231,0.329]$} & 0.280 & $\sqrt{ }$ & \\
\hline $\mathrm{B}_{8}$ & {$[0.199,0.386]$} & {$[0.141,0.214]$} & {$[0.340,0.599]$} & 0.470 & 20 & {$[0.058,0.172]$} & 0.115 & $\sqrt{ }$ & \\
\hline $\mathrm{B}_{9}$ & {$[0.152,0.298]$} & {$[0.028,0.093]$} & {$[0.181,0.390]$} & 0.285 & 29 & {$[0.124,0.205]$} & 0.164 & $\checkmark$ & \\
\hline $\mathrm{B}_{10}$ & {$[0.050,0.146]$} & {$[0.055,0.093]$} & {$[0.105,0.240]$} & 0.172 & 32 & {$[-0.004,0.053]$} & 0.024 & $\sqrt{ }$ & \\
\hline $\mathrm{B}_{11}$ & {$[0.169,0.352]$} & {$[0.139,0.264]$} & {$[0.308,0.616]$} & 0.462 & 22 & {$[0.030,0.088]$} & 0.059 & $\checkmark$ & \\
\hline $\mathrm{B}_{12}$ & {$[0.090,0.264]$} & {$[0.212,0.359]$} & {$[0.302,0.623]$} & 0.462 & 21 & {$[-0.122,-0.095]$} & -0.109 & & $\checkmark$ \\
\hline $\mathrm{B}_{13}$ & {$[0.486,0.905]$} & {$[0.512,0.923]$} & {$[0.998,1.828]$} & 1.413 & 2 & {$[-0.026,-0.018]$} & -0.022 & & $\sqrt{ }$ \\
\hline $\mathrm{B}_{14}$ & {$[0.586,1.025]$} & {$[0.870,1.444]$} & {$[1.456,2.468]$} & 1.962 & 1 & {$[-0.284,-0.419]$} & -0.352 & & $\sqrt{ }$ \\
\hline $\mathrm{B}_{15}$ & {$[0.238,0.444]$} & {$[0.229,0.408]$} & {$[0.467,0.852]$} & 0.660 & 16 & {$[0.009,0.036]$} & 0.023 & $\sqrt{ }$ & \\
\hline $\mathrm{B}_{16}$ & {$[0.058,0.090]$} & {$[0.0,0.027]$} & {$[0.058,0.117]$} & 0.087 & 34 & {$[0.058,0.063]$} & 0.060 & $\sqrt{ }$ & \\
\hline $\mathrm{B}_{17}$ & {$[0.228,0.436]$} & {$[0.024,0.043]$} & {$[0.252,0.479]$} & 0.365 & 26 & {$[0.204,0.393]$} & 0.299 & $\sqrt{ }$ & \\
\hline $\mathrm{B}_{18}$ & {$[0.096,0.186]$} & {$[0.149,0.380]$} & {$[0.245,0.566]$} & 0.406 & 23 & {$[-0.052,-0.194]$} & -0.123 & & $\sqrt{ }$ \\
\hline $\mathrm{B}_{19}$ & {$[0.108,0.258]$} & {$[0.082,0.186]$} & {$[0.190,0.444]$} & 0.317 & 27 & {$[0.026,0.072]$} & 0.049 & $\sqrt{ }$ & \\
\hline $\mathrm{B}_{20}$ & {$[0.060,0.187]$} & {$[0.047,0.123]$} & {$[0.107,0.310]$} & 0.208 & 30 & {$[0.013,0.063]$} & 0.038 & $\sqrt{ }$ & \\
\hline $\mathrm{B}_{21}$ & {$[0.291,0.514]$} & {$[0.212,0.470]$} & {$[0.503,0.984]$} & 0.744 & 11 & {$[0.079,0.044]$} & 0.062 & $\sqrt{ }$ & \\
\hline $\mathrm{B}_{22}$ & {$[0.114,0.241]$} & {$[0.410,0.696]$} & {$[0.524,0.937]$} & 0.731 & 12 & {$[-0.295,-0.455]$} & -0.375 & & $\sqrt{ }$ \\
\hline $\mathrm{B}_{23}$ & {$[0.302,0.554]$} & {$[0.159,0.363]$} & {$[0.461,0.917]$} & 0.689 & 14 & {$[0.144,0.190]$} & 0.167 & $\sqrt{ }$ & \\
\hline $\mathrm{B}_{24}$ & {$[0.109,0.196]$} & {$[0.130,0.327]$} & {$[0.239,0.523]$} & 0.381 & 24 & {$[-0.020,-0.131]$} & -0.076 & & $\sqrt{ }$ \\
\hline $\mathrm{B}_{25}$ & {$[0.148,0.310]$} & {$[0.393,0.706]$} & {$[0.541,1.016]$} & 0.779 & 9 & {$[-0.245,-0.395]$} & -0.320 & & $\sqrt{ }$ \\
\hline $\mathrm{B}_{26}$ & {$[0.398,0.685]$} & {$[0.216,0.455]$} & {$[0.614,1.140]$} & 0.877 & 7 & {$[0.182,0.230]$} & 0.206 & $\sqrt{ }$ & \\
\hline $\mathrm{B}_{27}$ & {$[0.054,0.109]$} & {$[0.312,0.567]$} & {$[0.365,0.675]$} & 0.520 & 19 & {$[-0.258,-0.458]$} & -0.358 & & $\sqrt{ }$ \\
\hline $\mathrm{B}_{28}$ & {$[0.146,0.249]$} & {$[0.0,0.0]$} & {$[0.146,0.249]$} & 0.198 & 31 & {$[0.146,0.249]$} & 0.198 & $\sqrt{ }$ & \\
\hline $\mathrm{B}_{29}$ & {$[0.112,0.221]$} & {$[0.389,0.697]$} & {$[0.501,0.918]$} & 0.709 & 13 & {$[-0.276,-0.476]$} & -0.376 & & $\sqrt{ }$ \\
\hline $\mathrm{B}_{30}$ & {$[0.054,0.116]$} & {$[0.046,0.126]$} & {$[0.100,0.242]$} & 0.171 & 33 & {$[0.008,-0.010]$} & -0.001 & & $\sqrt{ }$ \\
\hline $\mathrm{B}_{31}$ & {$[0.023,0.052]$} & {$[0.022,0.059]$} & {$[0.045,0.111]$} & 0.078 & 35 & {$[0.002,-0.006]$} & -0.002 & & $\sqrt{ }$ \\
\hline $\mathrm{B}_{32}$ & {$[0.326,0.620]$} & {$[0.200,0.375]$} & {$[0.526,0.995]$} & 0.761 & 10 & {$[0.126,0.245]$} & 0.186 & $\sqrt{ }$ & \\
\hline $\mathrm{B}_{33}$ & {$[0.363,0.642]$} & {$[0.212,0.388]$} & {$[0.575,1.030]$} & 0.803 & 8 & {$[0.152,0.254]$} & 0.203 & $\sqrt{ }$ & \\
\hline $\mathrm{B}_{34}$ & {$[0.233,0.437]$} & {$[0.247,0.454]$} & {$[0.480,0.891]$} & 0.685 & 15 & {$[-0.013,-0.016]$} & -0.015 & & $\checkmark$ \\
\hline $\mathrm{B}_{35}$ & {$[0.535,0.894]$} & {$[0.126,0.248]$} & {$[0.661,1.142]$} & 0.901 & 6 & {$[0.410,0.647]$} & 0.528 & $\checkmark$ & \\
\hline
\end{tabular}

construction, transportation and cranage cost $\left(\mathrm{B}_{2}\right)$, and shortage of market demand $\left(B_{5}\right)$. And the five least important barriers are small site dimensions in dense urban area $\left(\mathrm{B}_{31}\right)$, monotony of structure type $\left(\mathrm{B}_{16}\right)$, size and load restrictions on transportation $\left(\mathrm{B}_{30}\right)$, difficulty to the storage of prefabricated elements $\left(B_{10}\right)$, and lessons and attitudinal barriers due to historic failures $\left(\mathrm{B}_{28}\right)$.

The barriers can be divided to the "cause group" or the "effect group" based on the value of $\otimes R_{i}-\otimes C_{j}$. The results were presented in Table 6 . And according to the cause-effect diagram (Figure 1), the points above the $\mathrm{x}$-axis are the cause barriers, and the points below the $\mathrm{x}$-axis are the effect barriers. As a result, 19 barriers are in the cause group and 16 in the effect group. The cause barriers include: high initial set-up cost for manufacturer $\left(B_{1}\right)$, longer lead-in time for pre-planning and design during design stage $\left(\mathrm{B}_{6}\right)$, traditional design process unsuited to OSC $\left(\mathrm{B}_{7}\right)$, not easy to modify design scheme especially once manufacture has commenced $\left(\mathrm{B}_{8}\right)$, transportation technology of prefabricated elements and access to the construction site $\left(B_{9}\right)$, difficulty to the storage of prefabricated elements $\left(B_{10}\right)$, durability of prefabrication unproven $\left(B_{11}\right)$, organizational mechanism and culture $\left(B_{15}\right)$, monotony of structure type $\left(\mathrm{B}_{16}\right)$, monopoly of techniques $\left(\mathrm{B}_{17}\right)$, education and training still focused on current practices $\left(B_{19}\right)$, fragmented industry structure $\left(B_{20}\right)$, unable to achieve good communication and collaboration among parties $\left(\mathrm{B}_{21}\right)$, risk adverse culture $\left(B_{23}\right)$, lack of related organizations, such as local $\mathrm{R} \& \mathrm{D}$ institutes and services, testing institute to prefabricated components, experienced design consultancy and 
designers, manufacturers and suppliers of prefabricated components, and production facility logistics, etc. $\left(\mathrm{B}_{26}\right)$, lessons and attitudinal barriers due to historic failures $\left(B_{28}\right)$, lack of design codes and standards for prefabricated components $\left(\mathrm{B}_{32}\right)$, lack of construction quality acceptance criteria $\left(B_{33}\right)$, and lack of governmental regulations and incentives $\left(\mathrm{B}_{35}\right)$. The rest 16 barriers are the effect barriers.

\subsection{Cause barriers analysis}

The barriers in the cause group have more influence on the whole barriers system, because the performance of the cause barriers can impact the effect barriers. Considering the importance sequence, the cause barriers were ranked as follows: $\mathrm{B}_{35}>\mathrm{B}_{26}>\mathrm{B}_{33}>\mathrm{B}_{32}>\mathrm{B}_{21}>\mathrm{B}_{23}>\mathrm{B}_{15}$ $>\mathrm{B}_{7}>\mathrm{B}_{8}>\mathrm{B}_{11}>\mathrm{B}_{1}>\mathrm{B}_{17}>\mathrm{B}_{19}>\mathrm{B}_{6}>\mathrm{B}_{9}>\mathrm{B}_{20}>\mathrm{B}_{28}$ $>\mathrm{B}_{10}>\mathrm{B}_{16}$. The top cause barriers came from the legal and industrial dimensions. In the legal dimension, lack of governmental regulations and incentives $\left(B_{35}\right)$, lack of construction quality acceptance criteria $\left(\mathrm{B}_{33}\right)$, and lack of design codes and standards for prefabricated components $\left(\mathrm{B}_{32}\right)$ were identified as the main cause barriers. The importance scores of the three barriers are 0.9013, 0.8025, 0.7608 , respectively. As the OSC industry in China is still at the early development stage, there is a lack of market forces. Therefore, governmental regulations and incentives on the OSC implementation are urgently needed to help the OSC participants to reduce cost and risk.

The important cause barriers in the industrial dimension are: lack of related organizations $\left(\mathrm{B}_{26}\right)$, unable to achieve good communication and collaboration among parties $\left(B_{21}\right)$, risk adverse culture $\left(B_{23}\right)$, and fragmented industry structure $\left(\mathrm{B}_{20}\right)$. This result indicates that there is a scarcity of participants in China's current OSC industry, which could affect the integrity of the OSC supply chain. Individual parties in the OSC industry will not be capable of implementing OSC. Therefore, encouraging the coordination and participation of all the market players is a must.

In the technological dimension, ten out of fourteen factors were in the cause group. This result indicates that the technologies for the whole OSC process, including component design, prefabrication, transportation, and assembly, are seriously hindering the OSC development. Therefore, the promotion of OSC requires mature technology as well as close coordination of different stakeholders.

High initial set-up cost for manufacturer $\left(B_{1}\right)$ is the only cause barrier in the economic dimension. Compared with the participants in the traditional construction process, component manufacturer is an additional party in OSC. As the suppliers in the construction supply chain, the manufacturers are responsible for producing the prefabricated components. However, the huge amounts of investment for the factory facilities and equipment, as well as the uncertainty of the market demand and the risks of inadequate technical and managerial experience, have greatly increased the cost for the manufacturers. Therefore, both the high predictable and unpredictable costs make $\mathrm{B}_{1}$ a very important cause barrier.
In the social dimension, lessons and attitudinal barriers due to historic failures $\left(\mathrm{B}_{28}\right)$ is the only cause barrier. This result has its historical reason. Since 1950s, China began to introduce the prefabricated panel building technology from the Soviet Union. However, the building durability problems, such as crack, water leakage, and poor earthquake resistance, have left negative impressions on OSC practitioners. It is thus understandable why $\mathrm{B}_{28}$ became a cause barrier to OSC application.

\subsection{Effect barriers analysis}

Sixteen barriers in the effect group were influenced by the cause factors. They were ranked according to their relative importance, i.e., $\otimes R_{i}+\otimes C_{j}$ values, as follows: $\mathrm{B}_{14}>\mathrm{B}_{13}>$ $\mathrm{B}_{4}>\mathrm{B}_{2}>\mathrm{B}_{5}>\mathrm{B}_{25}>\mathrm{B}_{22}>\mathrm{B}_{29}>\mathrm{B}_{34}>\mathrm{B}_{3}>\mathrm{B}_{27}>\mathrm{B}_{12}>\mathrm{B}_{18}$ $>\mathrm{B}_{24}>\mathrm{B}_{30}>\mathrm{B}_{31}$. Dependence of traditional construction method $\left(B_{14}\right)$ is the most important effect factor, whereas small site dimensions in dense urban area $\left(B_{31}\right)$ is the least important factor among these effect barriers.

The five most important effect barriers came from the technological and economic dimensions. In the technological dimension, dependence of traditional construction method $\left(\mathrm{B}_{14}\right)$ and lack of practices and experiences $\left(\mathrm{B}_{13}\right)$ are the two most important barriers, which reached the two highest importance scores, i.e., 1.962 and 1.413, respectively. Although with the highest importance scores, $\mathrm{B}_{14}$ and $\mathrm{B}_{13}$ were identified as the effect barriers, because they are the generalization and representation of other technological factors. This result indicates that specific technical factors are still the most important barriers in OSC application. In addition, OSC participants concern about the possible risks caused by applying OSC and pursue short-term economic profit, and thus are reluctant to be the OSC pioneers. Therefore, the transformation of the traditional construction industry requires mandatary control by the government.

In the economic dimension, three out of five (i.e., $B_{4}$, $B_{2}, B_{5}$ ) were ranked in the top five most important factors. The importance scores for high bidding price for contractors $\left(\mathrm{B}_{4}\right)$, high cost for contractor including construction, transportation cost and cranage cost $\left(\mathrm{B}_{2}\right)$, and shortage of market demand $\left(B_{5}\right)$ are $1.197,1.080,0.974$, respectively, which indicates that the OSC practitioners believe that the high economic cost and shortage of market demand are the main obstacles hindering the implementation of OSC. Yet, the top ranked economic factors are all effect barriers. This is because the high economic cost is the result of inadequate development of technology, industry, society, and regulations. Shortage of market demand $\left(B_{5}\right)$ is another important effect factor, because OSC techniques are new to developing countries like China. The consumers might not be aware of OSC or might concern about the safety of OSC, and thus causes a low market demand.

In the industrial dimension, reluctance to innovation $\left(\mathrm{B}_{25}\right)$, unbalance and uncertainty between component supply and demand $\left(\mathrm{B}_{22}\right)$ and lack of skilled industrial worker $\left(B_{27}\right)$ are the most important effect barriers. The 
development of OSC requires huge amount of technical and managerial innovation. However, OSC participants are reluctant to innovation due to the large innovation investment, high risk, and illegal piracy. The uncertainty of the OSC market demand causes the risk of component demand and supply unbalance, which constitutes obstacles to the component production investment, technological innovation, and production plan development. The result also indicates that there is a severely scant amount OSC managers and workers, which may be caused by the lack of OSC practices, education and training.

In the social dimension, lack of awareness of prefabrication by the market and public $\left(\mathrm{B}_{29}\right)$ is the most important effect factor. The level of public awareness and acceptance for the prefabricated buildings is still relatively low. Therefore, it is essential to arouse awareness of OSC among the construction participants and the general public.

Inadequate skills qualifications $\left(\mathrm{B}_{34}\right)$ is the only effect barrier in the legal dimension. OSC certification is the product/result of the OSC development to a certain stage, which can thus be seen as an effect factor.

The obtained results were sent to the external committee for validation. The external committee includes two academic experts and one construction manager. Their feedbacks accepted all the results, and thus validated the results of this research.

\section{Theoretical and managerial implications}

This research proposed a new grey-DEMATEL-based methodology for identifying OSC barriers and understanding their cause-effect interrelationships. It is an innovative attempt to apply the combined DEMATEL method and grey set theory in the OSC domain. The OSC barriers often have complicated relationships, especially at the early development stage. Therefore, a lot of questions such as what the cause barriers are, what the effect barriers are, and whether the barriers have the same influence on OSC development, have yet to be answered. These questions are exactly what this research aims to solve. The results of this study identified the OSC barriers and classified them to cause and effect factors, and ranked them according to their importance level, which provided a theoretical basis for promoting the OSC development.

In addition, the research findings provided important strategic directions for OSC participants. The results of this study suggest focusing on the barriers in the cause group due to their influences on the effect group barriers. Therefore, specific managerial implications are suggested from the following six main perspectives:

- Launching policy measures and incentives to encourage participants to commit to the OSC development. For example, the government can provide preferential access to land or credit, tax reduction and exemption, and capital allowances to OSC participants. The development of OSC needs the supports from the government, especially when the OSC development is still at the initial stage, and resources and techniques cannot be obtained from the market conveniently or at a low price.

- Popularizing the OSC practices at large scales to accumulate practical experiences. For example, OSC can be mandatorily required in the land transaction or planning phase of new buildings. It is normal to encounter difficulties and setbacks during the OSC development process. But in practice, each party should work together to solve any new problems.

- Devoting more efforts in the systematic OSC technological innovation. Many technical problems still need to be resolved, such as industrialized design, new construction technology, transportation technology, crane technology, and component production, etc.

- Improving and coordinating the OSC industry chain. For example, fostering the main market players, such as research and development institutes and services, prefabricated component testing institutes, as well as experienced design consultancy, to achieve resource integration, mutual connection and information communication, collaborative innovation, and risk reduction.

- Improving OSC education and training. On the one hand, the technologies and management of OSC should be added to the school education. On the other hand, OSC training should be provided for the traditional construction workers in the building practices. In addition, more time, energy, and money should be invested to the OSC education and training.

- Increasing the market demand for prefabricated buildings. Market demand is the fundamental force driving the development of OSC. Therefore, the buildings constructed by the OSC approach must satisfy people's requirements on building quality and built environment improvement, energy and resources consumption reduction, and personalized needs, to attract consumers to choose prefabricated buildings rather than traditional ones.

\section{Conclusions, limitations, and future work}

It is necessary to identify the barriers that hinder the implementation of OSC, which can help the decision-makers or stakeholders to put forward appropriate measures to promote the development of OSC in developing countries. This research investigates a wide range of barriers through a comprehensive literature review and in-depth expert interviews. To rank the barriers in terms of their relative importance and examine their cause-effect relationships, a grey DEMATEL method was developed. According to the research results obtained from the grey DEMATEL analysis, effective advices were provided to decision-makers or stakeholders to promote the development of OSC. According to the priority order and the cause-effect relationships of the 35 barriers, the following aspects should be taken into deeper consideration: governmental regulations and 
incentives, practices and experiences, traditional construction method transformation, communication and collaboration among different parties and related organizations, increased innovation, education, and training, and market demand. In this study, the vagueness and deviation from the experts' judgments are overcome by using the grey set theory. Different views on the OSC barriers from multiple stakeholders are considered and combined to ensure the comprehensiveness and accuracy when determining the final direct-influenced matrix. The relative importance order and cause-effect relationships among the barriers can help policy-makers and stakeholders to put forward more effective measures for promoting the application of OSC.

However, limitations still exist. First, more groups of experts can participate in the decision-making process. But it may produce different results compared to this study. Second, different countries or regions might face with different OSC barriers. It is necessary to specify the research scope when applying this research methodology to other countries or regions, to get more targeted and reliable results for developing better OSC development strategies. For future studies, additional barriers can be considered to extend the current study. The current model is based on the personal judgment of the experts. For future studies, more statistical-based validation can be conducted.

\section{Acknowledgements}

This research is jointly supported by the National Natural Science Foundation of China under Grant 51708039; Young Talent Fund of University Association for Science and Technology in Shaanxi, China; Shaanxi Province Science Foundation for Youths (Grant No. 2017JQ7005); and the Fundamental Research Funds for the Central Universities (Grant No. 300102238621). Their support is gratefully acknowledged. The authors would like to thank the editors, reviewers, and experts for their time and constructive comments.

\section{Funding}

This work was supported by the National Natural Science Foundation of China under Grant 51708039; Young Talent Fund of University Association for Science and Technology in Shaanxi, China; Shaanxi Province Science Foundation for Youths under Grant 2017JQ7005; and the Fundamental Research Funds for the Central Universities under Grant 300102238621.

\section{Author Contributions}

Both authors were involved in conceiving the goals, objectives, and structure of the paper. Yanhu Han designed and performed the research. Yanhu Han and Lufan Wang both wrote the paper, as well as reviewed and edited the manuscript drafts.

\section{Disclosure Statement}

The authors declare no conflict of interest.

\section{References}

Arif, M.; Egbu, C. 2010. Making a case for offsite construction in China, Engineering, Construction and Architectural Management 17(6): 536-548. https://doi.org/10.1108/09699981011090170

Bacudio, L. R.; Benjamin, M. F. D.; Eusebio, R. C. P.; Holaysan, S. A. K.; Promentilla, M. A. B.; Yu, K. D. S.; Aviso, K. B. 2016. Analyzing barriers to implementing industrial symbiosis networks using DEMATEL, Sustainable Production and Consumption 7: 57-65.

https://doi.org/10.1016/j.spc.2016.03.001

Blismas, N.; Wakefield, R. 2008. Drivers, constraints and the future of off-site manufacture in Australia, Construction Innovation 9(1): 72-83. https://doi.org/10.1108/14714170910931552

Blismas, N. G.; Pendlebury, M.; Gibb, A.; Pasquire, C. 2005. Constraints to the use of off-site production on construction projects, Architectural Engineering and Design Management 1(3): 153-162. https://doi.org/10.1080/17452007.2005.9684590

Cheshmehzangi, A. 2016. China's new-type urbanisation plan (NUP) and the foreseeing challenges for decarbonization of cities: A review, Energy Procedia 104: 146-152. https://doi.org/10.1016/j.egypro.2016.12.026

Chien, K. F.; Wu, Z. H.; Huang, S. C. 2014. Identifying and assessing critical risk factors for BIM projects: Empirical study, Automation in Construction 45: 1-15. https://doi.org/10.1016/j.autcon.2014.04.012

Fontela, E.; Gabus, A. 1976. The DEMATEL observer. DEMATEL 1976 report. Geneva: Battelle Geneva Research Center.

Govindan, K.; Khodaverdi, R.; Vafadarnikjoo, A. 2016. A grey DEMATEL approach to develop third-party logistics provider selection criteria, Industrial Management \& Data Systems 116(4): 690-722. https://doi.org/10.1108/IMDS-05-2015-0180

Goodier, C. I.; Gibb, A. G. 2005. Barriers and opportunities for offsite in the UK, in CIB Helsinki International Joint Symposium "Systematic Innovation in the Management of Project and Processes", 148-158.

Han, Y.; Skibniewski, M. J.; Wang, L. 2017. A market equilibrium supply chain model for supporting self-manufacturing or outsourcing decisions in prefabricated construction, Sustainability 9(11): 2069. https://doi.org/10.3390/su9112069

Hong, J.; Shen, G. Q.; Li, Z.; Zhang, B.; Zhang, W. 2018. Barriers to promoting prefabricated construction in China: A costbenefit analysis, Journal of Cleaner Production 172: 649-660. https://doi.org/10.1016/j.jclepro.2017.10.171

Jaillon, L.; Poon, C. S. 2009. The evolution of prefabricated residential building systems in Hong Kong : A review of the public and the private sector, Automation in Construction 18(3): 239-248. https://doi.org/10.1016/j.autcon.2008.09.002

Kabak, Ö.; Ülengin, F.; Çekyay, B.; Önsel, Ş.; Özaydın, Ö. 2016. Critical success factors for the iron and steel industry in Turkey: A fuzzy DEMATEL approach, International Journal of Fuzzy Systems 18(3): 523-536. https://doi.org/10.1007/s40815-015-0067-7

Kumar, A.; Dash, M. K. 2016. Using DEMATEL to construct influential network relation map of consumer decision-making in e-marketplace, International Journal of Business Information Systems 21(1): 48-72. https://doi.org/10.1504/IJBIS.2016.073380

Li, Z.; Shen, G. Q.; Xue, X. 2014. Critical review of the research on the management of prefabricated construction, Habitat International 43: 240-249.

https://doi.org/10.1016/j.habitatint.2014.04.001 
Liang, H.; Ren, J.; Gao, Z.; Gao, S.; Luo, X.; Dong, L.; Scipioni, A. 2016. Identification of critical success factors for sustainable development of biofuel industry in China based on grey decision-making trial and evaluation laboratory (DEMATEL), Journal of Cleaner Production 131: 500-508. https://doi.org/10.1016/j.jclepro.2016.04.151

Lin, R.-J. 2013. Using fuzzy DEMATEL to evaluate the green supply chain management practices, Journal of Cleaner Production 40: 32-39. https://doi.org/10.1016/j.jclepro.2011.06.010

Lin, Y. H.; Lee, P. C.; Ting, H. I. 2008. Dynamic multi-attribute decision making model with grey number evaluations, Expert Systems with Applications 35(4): 1638-1644. https://doi.org/10.1016/j.eswa.2007.08.064

Lovell, H.; Smith, S. J. 2010. Agencement in housing markets: The case of the UK construction industry, Geoforum 41(3): 457-468. https://doi.org/10.1016/j.geoforum.2009.11.015

Mao, C.; Shen, Q.; Pan, W.; Ye, K. 2015. Major barriers to off-site construction: The developer's perspective in China, Journal of Management in Engineering 31(3): 04014043. https://doi.org/10.1061/(ASCE)ME.1943-5479.0000246

Mohamad Kamar, K. A.; Alshawi, M.; Abd Hamid, Z. 2009. Barriers to industrialized building system (IBS): the case of Malaysia, in $9^{\text {th }}$ International Postgraduate Research Conference on "Built and Human Environment", 2009, 1-16.

Pan, W.; Gibb, A. G.; Dainty, A. R. 2007. Perspectives of UK housebuilders on the use of offsite modern methods of construction, Construction Management and Economics 25(2): 183-194. https://doi.org/10.1080/01446190600827058

Patil, S. K.; Kant, R. 2014. Knowledge management adoption in supply chain: Identifying critical success factors using fuzzy DEMATEL approach, Journal of Modelling in Management 9(2): 160-178. https://doi.org/10.1108/JM2-08-2012-0025

Polat, G. 2010. Precast concrete systems in developing vs. industrialized countries, Journal of Civil Engineering and Management 16(1): 85-94. https://doi.org/10.3846/jcem.2010.08

Ren, J.; Manzardo, A.; Toniolo, S.; Scipioni, A. 2013. Sustainability of hydrogen supply chain. Part I: Identification of critical criteria and cause-effect analysis for enhancing the sustainability using DEMATEL, International Journal of Hydrogen Energy 38(33): 14159-14171.

https://doi.org/10.1016/j.ijhydene.2013.08.126

Tam, V. W. Y.; Tam, C. M.; Zeng, S. X.; Ng, W. C. Y. 2007. Towards adoption of prefabrication in construction, Building and Environment 42(10): 3642-3654. https://doi.org/10.1016/j.buildenv.2006.10.003

Tseng, M. L. 2009. A causal and effect decision making model of service quality expectation using grey-fuzzy DEMATEL approach, Expert Systems with Applications 36(4): 7738-7748. https://doi.org/10.1016/j.eswa.2008.09.011

Vakil alroaia, Y.; Hemati, M.; Javidnia, M. 2012. A new approach to develop entrepreneurship of the industry using fuzzy DEMATEL, Management Science Letters 2(4): 1279-1288. https://doi.org/10.5267/j.msl.2012.02.011

Zhang, X.; Skitmore, M. 2012. Industrialized housing in China: a coin with two sides, International Journal of Strategic Property Management 16(2): 143-157. https://doi.org/10.3846/1648715X.2011.638945

Zhou, Q.; Huang, W.; Zhang, Y. 2011. Identifying critical success factors in emergency management using a fuzzy DEMATEL method, Safety Science 49(2): 243-252.

https://doi.org/10.1016/j.ssci.2010.08.005 